\title{
Jogo da Trilha Topológica: Proposta de Convalidação na versão virtual
}

\author{
Carla V. M. Marques ${ }^{1}$, Carlo E. T de Oliveira ${ }^{1}$, Claudia L. R. Motta ${ }^{1}$, Letícia P. M. \\ da Cunha ${ }^{2}$, Marcelo Ramos ${ }^{2}$, Walter A. O. Bicalho. ${ }^{2}$ \\ ${ }^{1}$ Instituto Tércio Pacitti de Aplicações e Pesquisas Computacionais (NCE) - \\ Universidade Federal do Rio de Janeiro (UFRJ) - \\ Caixa Postal 15.064 - 91.501-970 - Rio de Janeiro - RJ - Brazil. \\ ${ }^{2}$ Programa de Pós-Graduação em Informática (PPGI) - Universidade Federal do Rio de \\ Janeiro (UFRJ) - Rio de Janeiro - RJ - Brazil. \\ \{claudiam, carlaveronica, carlo\} @nce.ufrj.br, \{lemedeiroseduc, \\ walterbicalho\} @hotmail.com, marceloxramos@yahoo.com.br.
}

\begin{abstract}
This study aims to analyze and understand how the process is functional and cognitive representations of the child in their interaction with virtual consoles games. Based on this principle we intend to validate the game Topological Trail, since it presents in versions with concrete and virtual application results in both. This game in its concrete version was analyzed by the research team of experimental Barbel Inhelder and Guy Cellérier in 1996. In its virtual version was applied and analyzed by researchers Neuropedagogia of Master's degree in Computer Science, the Tercio Pacitti Institute of Computer Applications and Research of the Federal University of Rio de Janeiro (UFRJ), in children and young people, in the Rio +20 agenda $\&$ You, inserted at the World Education Metacognitive.
\end{abstract}

Keywords: cognitive representations; virtual games; Topological game track.

Resumo. O presente estudo tem o objetivo de analisar e compreender como se constitui o processo funcional e as representações cognitivas da criança em sua interação com jogos virtuais. Partindo desse princípio pretendemos convalidar o jogo da Trilha Topológica, visto que se apresenta nas versões manipulável e virtual com resultados de aplicação em ambas. Este jogo em sua versão manipulável foi analisado pela equipe de pesquisa experimental de Barbel Inhelder e Guy Cellérier, em 1996. Em sua versão virtual foi aplicado e analisado por pesquisadores de Neuropedagogia do curso de mestrado em Informática, do Instituto Tércio Pacitti de Aplicações e Pesquisas Computacionais, da Universidade Federal do Rio de Janeiro (UFRJ), em crianças e jovens, na Agenda Rio +20 \& Você, inserido na Cúpula Mundial de Educação Metacognitiva.

Palavra-chave: representações cognitivas; jogos virtuais; jogo da Trilha Topológica 


\section{Introdução}

Este artigo apresenta resultados de pesquisa obtidos por pesquisadores de Neuropedagogia, vinculados ao Programa de Pós-Graduação em Informática, do Instituto Tércio Pacitti de Aplicações e Pesquisas Computacionais, da Universidade Federal do Rio de Janeiro (UFRJ). Nosso objetivo foi o de convalidar o jogo virtual da Trilha Topológica (Inhelder \& Cellérier, 1996) observando a estruturação do processo de representação cognitiva das crianças que participaram do experimento em sua interação com jogos virtuais a partir de crivos matemáticos. Comparamos os dados obtidos com a aplicação dos experimentos nas versões manipulável e virtual buscando convalidar o modelo virtual do experimento.

Para tanto, no segundo semestre de 2011 realizamos a leitura da obra "O Desenrolar das Descobertas da Criança: um estudo sobre as microgêneses cognitivas", de Bärbel Inhelder e Guy Cellérier que apresenta um estudo experimental constituído por quinze experimentos. Dentre eles, nos concentramos na análise dos seguintes experimentos: Móbile, Carvalho de Mambré, Os últimos Serão os Primeiros, Trajeto Espacial, Trilha Topológica, Nível da Água, Travessia do Rio, Prédios em Chamas e Montagem de Trilhos.

O livro apresenta relatos de situações experimentais, em que foram utilizados jogos manipuláveis para o estudo dos processos funcionais que intervêm quando o sujeito aplica seus conhecimentos em contextos lúdicos. De acordo com Inhelder (1996), "quando aplica à assimilação dos universos de problemas que encontra no curso de sua atividade adaptativa". Nessa perspectiva, nosso propósito não foi estudar a resolução de problemas, mas sim os processos funcionais utilizados no desenvolvimento metacognitivo.

No primeiro semestre de 2012 iniciamos a implementação dos jogos de Inhelder em versões virtuais, ou seja, em forma de games computacionais. Até o momento, já reconstruímos os jogos da Trilha Topológica e da Montagem de Trilhos, que foram aplicados em diversas crianças e jovens, na Agenda Rio +20 \& Você, inserido na Cúpula Mundial de Educação Metacognitiva. Este formato virtual nos permitiu realizar uma coleta refinada de dados cognitivos. Utilizamos uma plataforma virtual de aprendizagem colaborativa, para discutirmos e realizarmos a análise dos dados dos jogos virtuais.

A intenção desse grupo de pesquisadores foi a de convalidar os experimentos realizados por Barbel Inhelder. Essa experiência é importante pelo fato de fortalecer, reafirmar e inserir um novo olhar sobre esses experimentos no campo da Neurociência. Ela permitiu a construção de instrumentos de controle consciente do processo cognitivo, incluindo a reflexividade de uma regra gerada, tornando-se fonte para estruturação de qualquer tipo de lógica, o que podemos chamar de metacognição. A chamada metacognição (Seminério, 1985) se constitui no uso reflexivo da cognição, onde através da prática controlada desse processo, o ser humano torna-se capaz de estruturar a lógica e, por consequência, instituir o nexo recursivo como um caminho para a construção do conhecimento.

Neste trabalho, propomo-nos a analisar o jogo da trilha topológica, a fim de convalidar o seu modelo virtual. Para isso, utilizamos as informações sobre o funcionamento microgenético humano, já coletadas no banco de dados resultante do 
registro de informações do jogo em questão. Nosso texto está dividido em 4 partes. Em um primeiro momento destacamos a importância dos jogos para o desenvolvimento da criança, em seguida, apresentamos o jogo da Trilha Topológica na versão concreta e virtual e, finalmente analisamos os dados coletados durante a realização da Agenda Rio +20 \& Você, inserido na Cúpula Mundial de Educação Metacognitiva. Compararemos esses dados com os do jogo manipulável.

\section{O JOGO E O DESENVOLVIMENTO}

Partindo das situações experimentais utilizando jogos manipuláveis idealizados inicialmente por Piaget e posteriormente corroborados por Inhelder (1996), observamos que a cognição deriva do equilíbrio entre os processos de assimilação e acomodação. $O$ jogo permite que a criança adquira regras e imaginação simbólica de acordo com construções espontâneas que imitam o real. Nesse processo, o símbolo de assimilação individual dá passagem à regra coletiva ou ao símbolo representativo ou objetivo, ou a ambos.

O jogo possibilita a construção de conhecimentos e uma maior interação entre os indivíduos. De acordo com Brum e Binato (2004), “os jogos são apresentados como uma atividade natural no desenvolvimento dos processos psicológicos básicos, supõe um "fazer sem obrigação externa e imposta", embora demande exigências, normas e controle (PCN'S. p.48).”

A inserção do jogo nas atividades formais de ensino (Bruner \& Haste, 1987) se ancora na ideia de que ao jogar o ser humano seleciona, assimila, processa, interpreta e confere significações aos estímulos que provém da interação com os jogos. É preciso destacar também o papel do meio cultural como definidor das possibilidades de aprendizagem dos sujeitos. De acordo com os PCN (1997, p. 48-49) um "aspecto relevante nos jogos é o desafio genuíno que eles provocam no aluno, que gera interesse e prazer".

O jogo é uma atividade que pode ser essencial para o desenvolvimento do pensamento policêntrico, pois alimenta a imaginação, exploração, invenção, interação, descoberta, socialização, interlocução entre as diferentes áreas. Sua importância está na possibilidade que cria de aproximar a criança do conhecimento, levando-a a vivenciar "virtualmente" situações de solução de problemas similares as de seu cotidiano.

São ferramentas de ensino porque permitem a apreensão de regras, a sistematização do pensamento, a elaboração de estratégias, a representação, cálculo e a previsão de ações dos adversários etc., além de consentir a interação e a interlocução entre os sujeitos. O jogo é uma mutação do sentido da realidade, supõe comunicação e interpretação, exige um acordo sobre as regras. É um espaço social, pois é consequência de uma aprendizagem social e supõe significação conferida por seus participantes.

O público que participou do experimento do jogo virtual da Trilha Topológica tinha entre 04 e 12 anos de idade. Considerando os estágios de desenvolvimento apresentados por Piaget (1978) esses indivíduos apresentam estruturas cognitivas qualitativamente diferentes, que se modificam ao longo do processo de desenvolvimento (Goulart, 1987 e Moreira, 1999) e que possivelmente originariam comportamentos diferenciados na interação com o jogo. 
Esses participantes estariam situados em três estágios de desenvolvimentos definidos por Piaget (1978), como: Pré-operacional (2 a 6 anos); Operacional- concreto (7 a 11 anos) e Operacional-formal (a partir de 11 anos). No estágio Pré-operacional é esperado que a criança faça uso da linguagem, de símbolos e imagens mentais. Nessa fase, o seu pensamento começa a se organizar, mas ainda não é reversível. Entre cinco 5,5 e 7 anos acredita-se que eles já possuam regulações representativas articuladas e que estejam na fase intermediária entre a não conservação e a conservação. Eles começam a fazer a ligação entre os estados e as transformações, graças às regulações representativas permitindo pensá-las sob formas semireversíveis.

No estágio Operacional Concreto (Piaget, 1987) as crianças agem de acordo com uma lógica diretamente experimentada sobre os objetos reais, não sendo ainda capazes de operar com hipótese, mas já conseguem realizar algumas operações de reversibilidade. Finalmente, no estágio Operacional- formal espera-se que o indivíduo seja capaz de raciocinar com hipóteses verbais e que ao pensar, manipule proposições e opere mentalmente com elas.

Foi com esse olhar sobre o jogo manipulável e sobre a fase de desenvolvimento dos jogadores, que analisamos os dados do jogo da Trilha Topológica para observar processos cognitivos específicos.

\section{Jogo da Trilha Topológica - Versão Manipulável}

O jogo da Trilha Topológica é baseado em representações espaciais. O sujeito é convidado a ligar, através de um caminho, três casas situadas na periferia de uma superfície plana quadriculada (Ackermann-Valladão, 1980). A tarefa é construir um itinerário utilizando as placas com os segmentos de caminhos.

Para isso, se faz necessário: um tabuleiro quadriculado, com quadrados de $10 \mathrm{~cm}$ de lado, em cartolina ou outro material firme; três casas, também confeccionadas em cartolina ou outro material de sua preferência; e fichas em forma de quadrado, no mesmo tamanho do quadriculado do tabuleiro, com o desenho de segmentos de caminhos em três tipos: reta, em $\mathrm{T}$, em quina (cantoneira) como evidenciado nas figuras 1 e 2 .

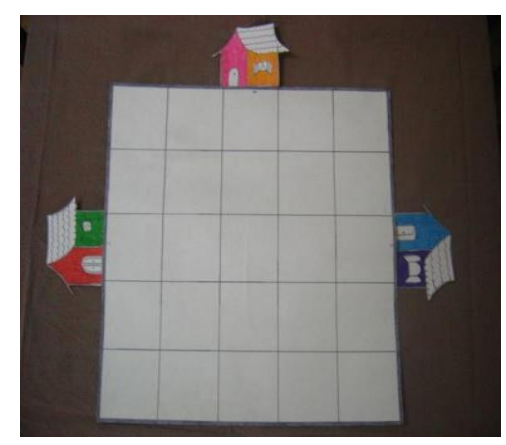

Figura 1 - Tabuleiro com as três casas 


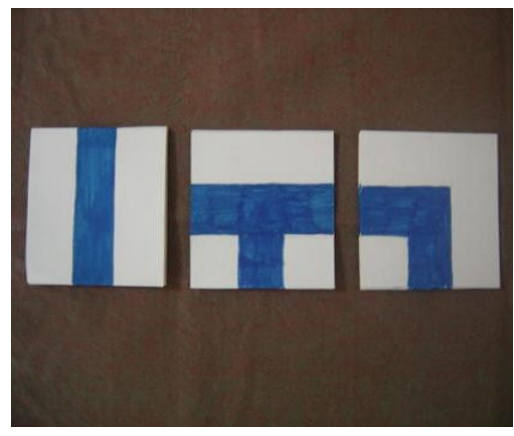

Figura 2 - Fichas de segmentos de caminho

O Jogo da Trilha Topológica é indicado para crianças de 4 a 12 anos. Ele permite a observação de como o sujeito planeja, escolhe um procedimento e resolve o desafio. Possibilita constatar se a criança leva em consideração as instruções na execução da tarefa, além de identificar situações observáveis: ações teleonômicas, ações causais e o FOK e não-observáveis: auto-correção, heurísticas, escolhas de ações.

\section{O Jogo da Trilha Topológica na versão virtual}

O Jogo da Trilha Topológica em sua versão virtual (Figura 3) segue as mesmas regras do jogo tradicional. No entanto, agora todo o processo de observação sobre os movimentos das peças feitas pelo jogador e de captura temporal são computados e alocados em variáveis específicas pelo próprio sistema. Isso permite que: a) seja possível a criação de uma quantidade necessária de crivos matemáticos que são registrados pelo computador e que, por sua vez, são responsáveis por capturar e armazenar todos os movimentos dentro do jogo além do tempo gasto entre cada um deles; b) uma maior precisão na captura das informações; c) uma captura mais consistente e precisa dos dados, pois o computador, diferente do ser humano, não se cansa; d) a qualidade dos dados capturados em um jogo virtual seja superior, se comparada à qualidade dos dados obtidos pelo modo convencional.

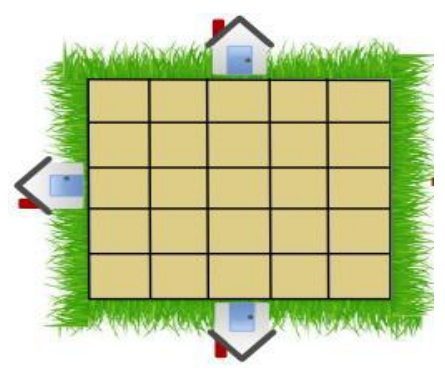

Figura 3 - Tabuleiro virtual com as três casas

Este processo de captura inteligente dos dados gerou uma planilha de dados que, por meio de informações estatísticas, nos permitiram analisar as representações cognitivas registradas nos crivos matemáticos. Vê-se então que a potencialização de um jogo, em uma versão virtual pode facilitar o processo de tratamento e análise dos dados.

O jogo da Trilha Topológica também possui uma versão Tridimensional (Figura 4). Nela, além das vantagens anteriormente citadas, o jogador tem a opção de rotacionar o tabuleiro quantas vezes quiser a fim de obter um melhor ângulo de visualização 
(Figura 5). Esta atualização possibilita a captura de informações sobre esta variação do Nível Semiótico. Logo, novos crivos matemáticos poderão ser criados a fim de registrar os impactos que esta variante poderá causar nos processos cognitivos do jogador.

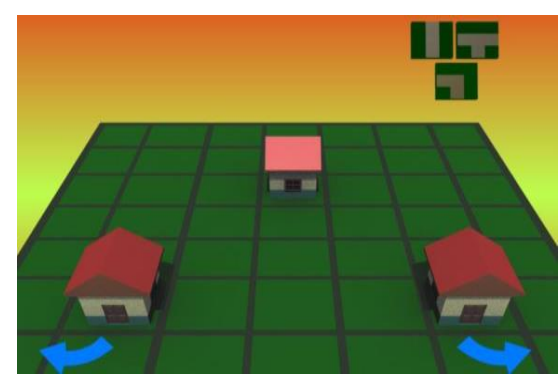

Figura 4 - Imagem Frontal

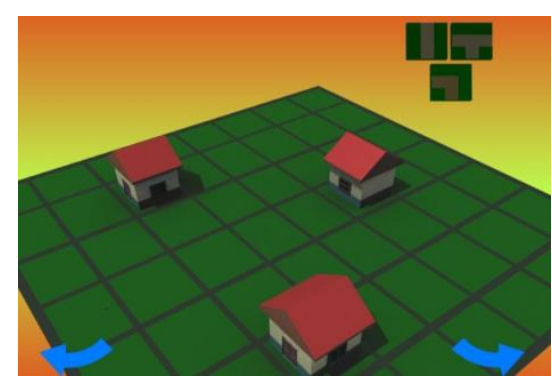

Figura 5 - Imagem Rotacional

\section{Validação do experimento}

Com o experimento da trilha topológica, Inhelder (1996) buscou observar como os participantes organizaram os procedimentos utilizados na resolução da situação problema apresentada. De acordo com a autora (1996, p. 65) para que o participante conseguisse realizar a tarefa seria primordial que fizesse representações espaciais do conjunto do tabuleiro e dos pontos que precisaria unir. Assim, teria condições de visualizar as possíveis conexões que precisaria fazer considerando os tipos e a quantidade de peças de que dispunha.

A autora sinaliza que o participante deveria "circular entre as diferentes formas de representação, espaciais e temporais, para poder identificar as suas peças, compreender as suas funções e localizá-las corretamente”. Inhelder (1996, p. 65) destaca que "o êxito na tarefa supõe que o sujeito, à medida em que avança, saiba "entrar e sair do quadriculado". Em sua análise do jogo manipulável ela destacou 4 diferentes conjuntos de procedimentos em que se sobressaíriam diferentes representações.

O primeiro deles se refere a resolução do problema em que os participantes partiriam de uma das casas e seguiriam a borda da grade a fim de alcançarem as outras casas sem muita necessidade de planejamento das ações. A este procedimento Inhelder nomeou como Procedimento "pelas bordas." O segundo processo compreende a situação em que o participante se preocupa em ligar apenas duas casas e não dá atenção para o objetivo de ligar a terceira casa também. Ele foi classificado pela autora como Articulação não-planejada de dois procedimentos. 
A chamada Integração do segundo subobjetivo é o terceiro conjunto de procedimentos definido pela autora. Nele, o participante antecipa uma abertura para ligar a terceira casa. No início ou no decorrer do processo, ele se dá conta de que deve utilizar o "T" para abrir o acesso a terceira casa. No último procedimento "Cercamento" do ponto de interseção a partir dos objetivos o participante constrói simultaneamente, por meio dos pontos de chegada (casas) três eixos de ligação.

Com a versão virtual do jogo da trilha topológica observamos as ações que os participantes desenvolviam para atingir o objetivo do jogo, como planejavam e reorganizam suas peças de acordo com os obstáculos que se apresentavam. Nossa intenção não era somente a de confirmar o que já tinha sido assinalado por Inhelder (1996), mas também de criar um instrumento que permitisse ampliar a observação sobre como o sujeito utiliza e constrói o seu conhecimento.

A versão virtual do jogo da trilha topológica permitiu que observássemos como os participantes, na medida em que avançavam na idade iam refinando as suas ações e procedimentos de resolução da situação problemas a partir do planejamento das ações. Observamos as modificações ocorridas durante a resolução da situação problema ressaltando a passagem, a singularidade e as diferentes estratégias adotadas para resolução do problema formuladas pelos participantes de acordo com a sua fase de desenvolvimento.

Os gráficos a seguir evidenciam que os participantes entre 9 e 13 anos são os que demonstraram procedimentos de resolução da situação problema classificadas por Inhelder (1996) como "Cercamento" do ponto de interseção a partir dos objetivos. Nesse caso o "T" é colocado inicialmente no eixo de interseção e posteriormente são montados os caminhos em linha reta em direção as casas.
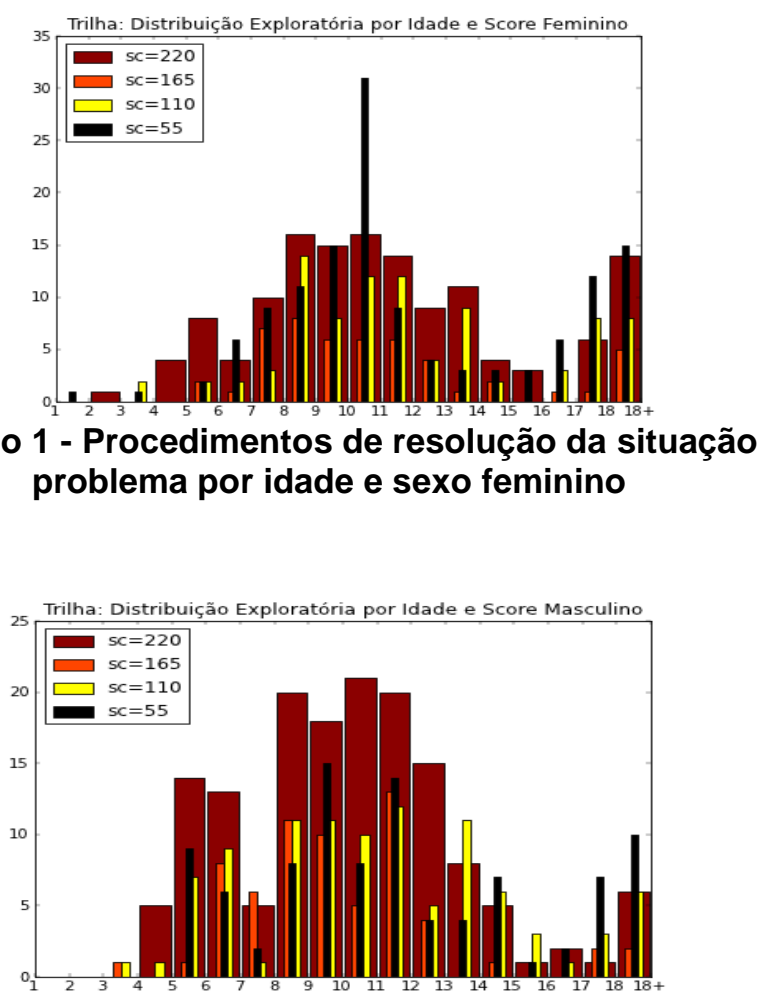


\section{Gráfico 2 - Procedimentos de resolução da situação problema por idade e sexo masculino}

Entretanto, nessa faixa etária, principalmente no grupo feminino, também se concentram as soluções em que os participantes não alcançaram ou alcançam os objetivos do jogo utilizando um maior número de peças. Podemos inferir que adotaram os procedimentos nomeados por Inhelder como Procedimento "pelas bordas" e "Articulação não-planejada de dois procedimentos" em que não há uma preocupação maior com o planejamento das ações.

Deduzimos que nesses casos, os participantes não conseguem, tal como sinalizado pela autora fazer a representação espacial do conjunto do tabuleiro e das peças que deveriam unir visualizando as melhores conexões para solução do problema.

Esses dados permitem a percepção do movimento presente na passagem das fases Operacional concreta para a fase das Operações formais criadas por Piaget. Os dados capturam esse movimento de passagem de uma fase de desenvolvimento para outra. Indivíduos com idades parecidas adotam diferentes estratégias e procedimentos para resolução do problema. Uns apresentam soluções mais ligadas à experiência material e intuitiva e outros já conseguem planejar suas ações a partir de uma visão do todo.

Esse momento de passagem de conhecimentos gerais para os mais elaborados também é evidenciada nos gráficos apresentados a seguir. Podemos verificar que nas classes 2 e 3 (Gráfico 3) há uma maior manipulação das peças, o que configura uma ação maior sobre o concreto para aprimorar as estratégia de resolução do problema e atingimento dos objetivos propostos. Os participantes tendem a organizar as peças a partir das associações que já fizeram estando mais ligada a realidade imediata e concreta do jogo.

Na Classe 4 (Gráfico 3) vemos que os sujeitos já conseguem pensar, planejar melhor a ação antes de executá-la atingindo o objetivo com maior rapidez e eficiência. Já desenvolveram com maior propriedade sua capacidade de interiorização do pensamento e não precisam mais do concreto para planejar as estratégias que utilizarão para resolver a situação-problema. Tal como o experimento concreto realizado por Inhelder (1996), o jogo virtual permitiu que observássemos os procedimentos adotados pelos sujeitos a partir de suas experiências práticas sobre o jogo. Ele nos forneceu indicações sobre o funcionamento do estágio pré-operacional, definido por Piaget, em que o sujeito se desenvolve pela sua ação sobre a realidade e pela representação. Com o jogo virtual nós conseguimos captar alguns elementos presentes nessa mudança. 

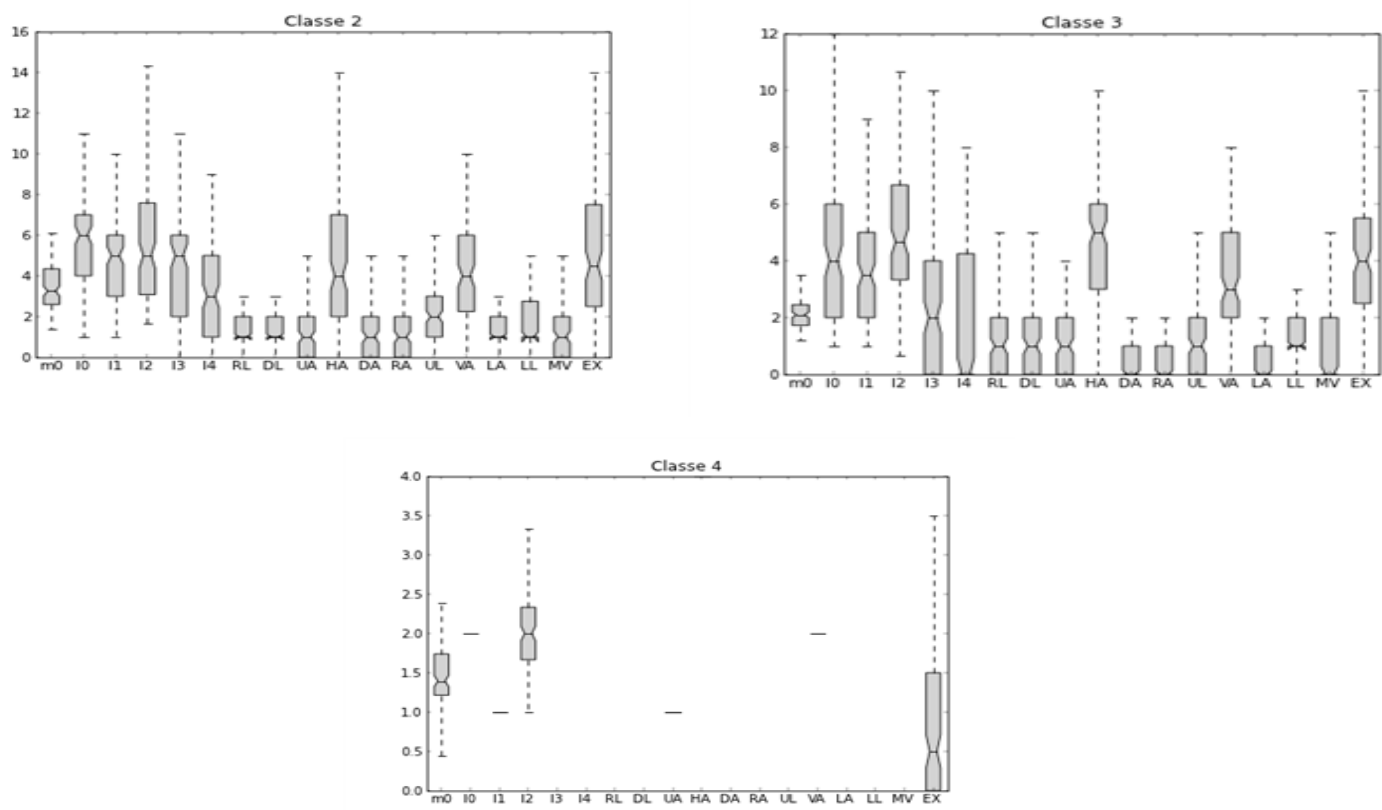

\section{Gráfico 3 - Os gráficos são demonstrativos de aprimoramento das estratégias de resolução do problema e atingimento dos objetivos propostos}

A autora (Inhelder, 1996) sinaliza que um estudo que objetiva observar a microgênese deve "analisar as condutas cognitivas em pormenor e em toda a sua complexidade natural exige um acompanhamento progressivo dos participantes, uma postura objetiva de observação e registro videográficos" (Inhelder, 1996, p. 12). Compreendemos que o jogo virtual vai além dessas expectativas e aprimora tanto a técnica quanto a quantidade de dados coletados.

A versão virtual do jogo também permitiu que os dados fosse analisados a partir da "descrição comentada das condutas", fornecendo informações sobre as diferentes fases da realização, analisar as modificações no curso da ação e, enfim, inferir os modelos subjacentes a sua organização funcional” (Inhelder, 1996, p. 13).

\section{Conclusão}

Neste artigo apresentamos os resultados da comparação da aplicação do jogo da Trilha Topológica (Inhelder \& Cellérier, 1996) nas versões manipulável e virtual. Observamos a estruturação do processo de representação cognitiva das crianças que participaram do experimento em sua interação com jogos virtuais a partir de crivos matemáticos.

A partir deste estudo podemos verificar que a utilização de um jogo virtual apresenta ganhos em relação a precisão dos dados capturados pelo computador. Isso é um fator que pode ser levado em conta quando comparamos a um jogo manipulável que permite que a criança utilize os sentidos do tato, por exemplo. Uma clara vantagem que potencializa o processo do jogo é a estrutura de um crivo automatizado, produzido por especialistas da área da educação ou psicólogos, devidamente configurado para capturar ações observáveis com exatidão de modo a dar margem para futuras inferências sobre os resultados. 


\section{Referências}

ACKERMANN-VALLADAO, E. (1980). “Tools for constructive learning. Rethinking interactivity". Cambridge: Media Lab - MIT.

BRASIL. Secretaria de Educação Fundamental. (1997). "Parâmetros curriculares nacionais: introdução aos parâmetros curriculares nacionais". Secretaria de Educação Fundamental. Brasília : MEC/SEF.

BRUM, M. de A.; BINATO, D. de O. dos S. (2004). "Aritmética e álgebra: construindo conceitos e suas relações". In: ENCONTRO NACIONAL DE EDUCAÇÃO MATEMÁTICA, 8., Recife. Anais.... Disponível em:

$<$ http://www.sbem.com.br/files/viii/pdf/04/MC24789097072.pdf $>$ Acesso em: 20 mar. 2014.

BRUNER, J.S., \& HASTE, H. (Ed.). (1987). "Making sense: The child's construction of the world". New York: Methuen.

GOULART, I.B. (1987). "Psicologia da Educação: Fundamentos Teóricos e Aplicações Práticas". Petrópolis, RJ: Vozes.

INHELDER, B. \& CELLÉRIER, G. (1996). “O desenrolar das descobertas da criança: um estudo sobre as microgêneses cognitivas". Artes Médicas. Porto Alegre, RS..

MARQUES, C.V.M.; MOTTA C.R.L; OLIVEIRA, C.E.T. (2009). Relatório Técnico Neuropedagogia 1. "A revolução cognitiva: Um estudo sobre a teoria de Franco Lo Presti Seminério". Rio de Janeiro, IM /NCE / UFRJ.

. (2011). Relatório Técnico - Neuropedagogia 3. "Análise cognitiva estrutural, funcional e linguística de procedimentos lógicos microgenéticos do conhecimento, na solução de problemas". Rio de Janeiro, IM /NCE / UFRJ.

MOREIRA, M. A. (1999). “Aprendizagem significativa”. Brasília: Editora Universidade de Brasília.

PIAGET, J. (1971). “A formação do símbolo na criança, imitação, jogo, sonho, imagem e representação de jogo”. São Paulo: Zanhar.

(1978). “A Epistelomogia Genética; Sabedoria e Ilusões da Filosofia; Problemas de Psicologia Genética". In: Piaget. Traduções de Nathanael C. Caixeiro, Zilda A. Daeir, Celia E.A. Di Pietro. São Paulo: Abril Cultural, 426p. (Os Pensadores).

- (1987). "A Psicogênese dos Conhecimentos e a sua Significação Epistemológica”. Teorias da Linguagem, Teorias da Aprendizagem. Lisboa: Edições.

SEMINÉRIO, F.L. (1985). “Avaliação da eficácia do método de modelação lógicoelementar no ensino pré-escolar". Rio de Janeiro: Projeto de Pesquisa. FGV. 